- Original Article

\title{
The Effect of Adding Honey to Zinc in the Treatment of Diarrhea in Children
}

\author{
Abolfazl Mahyar ${ }^{1 * *}$, Parviz Ayazi ${ }^{1}$, Mohammad Reza Shaftaroni ${ }^{1}$, Sonia Oveisi', Reza Dalirani ${ }^{2}$, Shiva Esmaeili' \\ 'Department of Pediatrics, Qazvin University of Medical Sciences, Qazvin, Iran \\ ${ }^{2}$ Department of Pediatrics, Shahid Beheshti University of Medical Sciences, Tehran, Iran
}

Background: Honey has been used in medicine since ancient times. Limited reports are available to indicate its antibacterial, antiviral, and antidiarrheal properties. This study aimed to determine the effect of honey on acute diarrhea in children.

Methods: This randomized clinical trial included 80 children with acute diarrhea. Forty children received honey and zinc gluconate (trial group) and 40 received only zinc gluconate (control group). After treatment, vomiting/diarrhea duration, the recovery time, and the duration of hospitalization were compared between the groups.

Results: Among the 40 children in the trial group, 19 were male and 21 were female. In the control group, 25 children were male and 15 female $(\mathrm{P}=0.26)$. After initiating treatment, the duration of diarrhea, recovery time, and the duration of hospitalization was significantly shorter in the trial group than in the control group $(\mathrm{P}<0.05)$.

Conclusion: This study showed that honey with zinc gluconate reduces the duration of diarrhea, accelerates the recovery time, and shortens the duration of hospitalization.

Keywords: Acute Diarrhea; Child; Honey; Zinc

Received: April 8, 2021, Revised: June 1, 2021, Accepted: June 25, 2021

*Corresponding Author: Abolfazl Mahyar https://orcid.org/0000-0002-6418-6372

Tel: +98-2813334807-9, Fax: +98-2813344088, E-mail: abolfazl473@yahoo.com 


\section{INTRODUCTION}

Diarrhea is a major cause of morbidity and mortality among children. It is more prevalent in developing countries than in developed countries. ${ }^{1,2)}$ Nine percent of child deaths (700,000 child deaths per year) are due to diarrhea, and it is the second leading cause of death among children. ${ }^{2)}$ It has been reported that the number of cases of diarrhea in children under the age of 5 years in developing countries is approximately 1,731 billion, and $80 \%$ of these children live in African and southeastern countries. ${ }^{2)}$ Although the mortality rates due to diarrhea have been recently reduced by therapeutic and preventive actions, ${ }^{1-3)}$ the overall incidence of diarrhea has only declined from 3.4 to approximately 2.9 episodes per child/y in the past 2 decades. ${ }^{2)}$ Acute diarrhea is the most common type of diarrhea in children and refers to a watery or loose stool that occurs 3 times or more in 24 hours and lasts less than 14 days. ${ }^{1-3)}$ It has been reported that $14 \%$ of children referred to the UK clinical centers had experienced acute diarrhea and 50,000 children are hospitalized annually due to acute diarrhea. ${ }^{3)}$ The most important etiologies of acute infectious diarrhea in children are viral (rotavirus) and bacterial (Escherichia. coli and Shigella). ${ }^{2)}$ The main treatment of acute diarrhea is fluid and electrolyte correction, and in some cases, antibiotic therapy may be indicated..$^{1-3)}$ A study of Haffejee and Moosa $^{4)}$ has also shown that the administration of honey can reduce the duration of acute diarrhea due to bacterial and viral infections. Honey has been used as food and medicine for a long time and is a byproduct of flower nectar and bee digestive function. ${ }^{4-6)}$ Honey has more than 600 different substances and its composition depends on the source of the plant from which it is extracted. ${ }^{5-7)}$ Some reports have pointed to the antimicrobial, antiviral, anti-inflammatory, and antioxidant effects of honey. ${ }^{5-7)}$ Given the high prevalence of acute diarrhea and the need for effective auxiliary treatments, this study was conducted.

\section{METHODS}

\section{Study Population}

This randomized clinical trial included 80 children with acute diarrhea. This study was conducted in the Qazvin Children Hospital. This hospital is the only children's referral hospital and is affiliated with Qazvin University of Medical Sciences (Qazvin, Iran). The inclusion criteria were as follows: (1) the existence of acute diarrhea (watery or loose stool 3 times or more in 24 hours and last less than 14 days $)^{1,2)}$; (2) age between 1 and 5 years; (3) mild to moderate dehydration; and (4) no use of antibiotics, zinc, or honey in the previous month. Children with chronic diarrhea (more than 14 days), bacterial and parasitic infections, severe dehydration ( $\geq 9 \%$ ), abdominal distension, intestinal obstruction, a history of allergy to proteins, and concomitant and underlying diseases, such as inflammatory bowel diseases, malnutrition, diabetes, and malabsorption diseases were excluded.

\section{Study Design}

Based on a previous study on the effect of honey on acute diarrhea ${ }^{6)}$ and statistical calculations to provide $1-\beta=0.9$ (Power), 80 children with acute diarrhea (40 children each in the case and control groups) were studied. After the approval of the project by the ethics committee of the university and obtaining consent from parents, the eligible children were divided into two groups by using balanced block randomization. We randomly allocated patients to the control or intervention groups using 20 blocks A, B (AABB, $\mathrm{ABAB}$, etc.) of the balanced blocked randomization method. A random number table from statistical textbooks was chosen to sort the blocks. Thereafter, the randomization group was written on paper and placed in an opaque sealed envelope. Once the patient consented to participate, the sealed envelope was opened by the physician. The trial group (40 patients) received honey and zinc gluconate, and the control group (40 patients) received only zinc gluconate. Honey was administered at a dose of $1.5 \mathrm{~mL}$ every 6 hours to children aged 1-3 years and $2 \mathrm{~mL}$ every 6 hours to children aged 3-5 years (Pajohesh honey, multi-floral origin; Deniz Co., Takestan, Iran; code number:12.12369). For easy swallowing of the honey, it was diluted in $15 \mathrm{~mL}$ of water each time. The zinc gluconate syrup was administered at a dose of $5 \mathrm{~mL}$ (equal to $5 \mathrm{mg}$ of zinc elemental) every 6 hours (20 mg daily) (zinc gluconate syrup; Amin Pharmaceutical Co., Isfahan, Iran; medicine register number: 7004300400003, Bach no: 06260154967626). ${ }^{2,6)}$ For flavoring of the zinc gluconate syrup in the control group, an authorized flavoring substance was used. The bottles of the solutions were similar in shape and size and color and taste in both groups. Parents and children were not aware of the type of the solution. The patients who vomited within 15 minutes received the drug again. Honey was administrated to the trial group for 5 days and zinc gluconate was administered to trial and control groups for 10 days. After initiating the treatment, the data about the duration of vomiting, frequency of diarrhea, duration of diarrhea, recovery time, and duration of hospitalization were recorded according to a checklist. The primary outcomes were the duration of diarrhea and recovery time and secondary outcomes were the duration of hospitalization and recurrence of diarrhea. The duration of diarrhea was defined as the time that the patient had acute diarrhea. ${ }^{1,2)}$ The recovery time was defined as the number of hours from the initiation of treatment to when normal soft stools were passed, with the patient showing normal hydration and satisfactory weight gain. ${ }^{2,6)}$ The normal stool was defined when the child had less than three defecations per day with a smooth and soft consistency, ${ }^{2,7)}$ Fluid therapy was performed in both groups in a standard and uniform manner. The weight, height, and head circumference (for children up to 3 years) were measured using a standard method. ${ }^{2)}$ Dehydration was divided into three types: minimal $(<3 \%)$, mild to moderate (3\%-9\%), and severe $(>9 \%){ }^{2)}$ All laboratory tests were carried out at the laboratory department of Qazvin Children Hospital.

\section{Statistics}

The chi-square test was used for the comparison of qualitative vari- 
ables, and Student t-test (mean \pm standard deviation [SD]), the MannWhitney U-test, and theWilcoxon test (median [interquartile range]) were used to compare quantitative variables between groups before and after the intervention. All statistical analyses were performed using SPSS for Windows ver. 16.0 (SPSS Inc., Chicago, IL, USA). Statistical significance was set at $\mathrm{P}<0.05$.

\section{Ethical Approval}

This project was approved by the ethics committee of Qazvin University of Medical Sciences (IR.QUMS.REC.1395.92). Also, the project was registered at the Iranian Registry of Clinical Trials (IRCT20160803 12897N1). All parents were provided with information regarding the research method in a simple language. Children were included in the study after their parents agreed and signed an informed consent form.

\section{RESULTS}

Among the 40 children in the trial group, 19 were males and 21 were females, whereas, the control group consisted of 25 males and 15 females $(\mathrm{P}=0.26)$. The mean $\pm \mathrm{SD}$ of age in the trial and control groups were 26.2 \pm 9.6 months and $22.4 \pm 8.9$ months, respectively $(\mathrm{P}=0.07)$. There was no significant difference between the two groups in terms of sex, age, the severity of dehydration, the type of diarrhea, and other variables before the intervention ( $\mathrm{P}>0.05)$ (Table 1$)$.

After the treatment, the duration of diarrhea in the trial group was

Table 1. Comparison of variables between case and control group before intervention

\begin{tabular}{|c|c|c|c|}
\hline Characteristic & $\begin{array}{l}\text { Case group } \\
\qquad(\mathrm{n}=40)\end{array}$ & $\begin{array}{l}\text { Control group } \\
\qquad(\mathrm{n}=40)\end{array}$ & P-value \\
\hline Gender* & & & 0.26 \\
\hline Male & 19 & 25 & \\
\hline Female & 21 & 15 & \\
\hline Age $(\mathrm{mo})^{\dagger}$ & $26.2 \pm 9.6$ & $22.4 \pm 8.9$ & 0.07 \\
\hline Weight $(\mathrm{kg})^{\dagger}$ & $11.5 \pm 2.0$ & $10.7 \pm 2.0$ & 0.08 \\
\hline Height $(\mathrm{cm})^{\dagger}$ & $87 \pm 8.1$ & $83.2 \pm 10.3$ & 0.07 \\
\hline Head circumference $(\mathrm{cm})^{\dagger}$ & $47.9 \pm 2.4$ & $47.8 \pm 2.5$ & 0.92 \\
\hline Duration of diarrhea $(\mathrm{d})^{\ddagger}$ & $2(2)$ & $3(2)$ & 0.77 \\
\hline Frequency of vomiting (daily) ${ }^{\ddagger}$ & $3.5(4.13)$ & $4.5(5.98)$ & 0.44 \\
\hline Duration of vomiting $(h)^{\ddagger}$ & $27.5(59.75)$ & $24.5(43.25)$ & 0.78 \\
\hline Frequency of diarrhea (daily) ${ }^{\dagger}$ & $5.1 \pm 4.1$ & $5.8 \pm 3.4$ & 0.43 \\
\hline Duration of diarrhea $(\mathrm{d})^{\ddagger}$ & $1(2)$ & $2(2)$ & 0.52 \\
\hline Dehydration severity* & & & 0.58 \\
\hline Mild & 10 & 7 & \\
\hline Moderate & 30 & 33 & \\
\hline Type of acute diarrhea* & & & 0.82 \\
\hline Bacterial & 23 & 22 & \\
\hline Viral & 17 & 18 & \\
\hline White blood cell count $\left(10^{9} / \mathrm{L}\right)^{\dagger}$ & $11.6 \pm 5.5$ & $10.3 \pm 4.0$ & 0.25 \\
\hline $\begin{array}{l}\text { Erythrocyte sedimentation rate } \\
(\mathrm{mm} / \mathrm{h})^{\ddagger}\end{array}$ & $13(16.20)$ & $10.5(18.75)$ & 0.38 \\
\hline C-reactive protein $(\mathrm{mg} / \mathrm{dL})^{\ddagger}$ & $11.1(22.30)$ & $8.2(20.12)$ & 0.37 \\
\hline
\end{tabular}

Values are presented as number of frequency, mean \pm standard deviation, or median (interquartile range).

*By chi-square test. ${ }^{\dagger}$ By t-test. ${ }^{*}$ By Mann-Whitney U-test. significantly shorter than that in the control group (18 \pm 25 versus $24.5 \pm 57$ hours, $\mathrm{P}=0.02$ ). Although the duration of vomiting in the trial group was shorter than that in the control group, the difference was not significant $(\mathrm{P}=0.34)$. The recovery time in the trial group was significantly shorter than that in the control group $(24 \pm 30$ versus $38 \pm 76$ hours, $\mathrm{P}=0.02$ ). Furthermore, the duration of hospitalization in the trial group was significantly shorter than that in the control group $(19 \pm 22$ versus 43.5 \pm 84.5 hours) (Table 2). Weight comparison of each group before and after the intervention showed significant differences $(\mathrm{P}=0.001)$ (Table 3). Follow-up of patients showed no recurrence of diarrhea in either group.

\section{DISCUSSION}

Although the main treatment of acute diarrhea is the correction of fluid and electrolytes, researchers have been trying to find a new supplementary treatment that can accelerate the improvement of diarrhea and prevent serious complications. ${ }^{1-8)}$ Studies regarding the role of honey in the treatment of acute diarrhea are rare. ${ }^{4,6)}$ Haffejee and Moosa $^{4)}$ studied 160 infants and children aged between 8 days and 11 years with acute gastroenteritis and revealed that the administration of honey reduces the duration of bacterial diarrhea and does not increase the duration of non-bacterial diarrhea. The authors recommended using honey instead of glucose in oral rehydration solutions. In the study by Haffejee and Moosa, ${ }^{4} 89$ children received oral rehydration solutions with the recommended formula of the World Health Organization/United Nations Children's Fund (control group) and 80 children received a similar oral rehydration solution, which used 50 $\mathrm{mL}$ pure honey per liter instead of glucose (trial group). Abdulrhman et al. ${ }^{6)}$ studied 100 infants and children aged 2 to 7 years with acute gastroenteritis and showed that adding honey to the oral rehydration solution reduced the duration of diarrhea and vomiting, as well as promoted rapid restoration of dehydration. In this study, the control group received the oral rehydration solution and the trial group received the oral rehydration solution and honey. Abdulrhman et al. ${ }^{6}$

Table 2. Comparison of variables between case and control group after intervention

\begin{tabular}{lccc}
\hline \multicolumn{1}{c}{ Variable } & $\begin{array}{c}\text { Case group } \\
(\mathrm{n}=40)\end{array}$ & $\begin{array}{c}\text { Control group } \\
(\mathrm{n}=40)\end{array}$ & P-value \\
\hline Duration of vomiting (h) & $2.0(9.0)$ & $4.0(20.0)$ & 0.34 \\
Duration of diarrhea (h) & $18.0(25.0)$ & $24.5(57.0)$ & 0.02 \\
Recovery time (h) & $24.0(30.0)$ & $38.0(76.0)$ & 0.013 \\
Duration of hospitalization (h) & $19.0(22.0)$ & $43.5(84.5)$ & 0.001 \\
\hline
\end{tabular}

Table 3. Weight before and after intervention in case and control groups

\begin{tabular}{lcc}
\hline Weight $(\mathrm{kg})$ & Case group & Control group \\
\hline Before & $11.2(3.0)$ & $10.2(2.7)$ \\
After & $11.5(3.0)$ & $10.5(3.0)$ \\
P-value & 0.001 & 0.001
\end{tabular}

Values are presented as median (interquartile range). By Wilcoxon test. 
showed that the recovery time in the group receiving te horal rehydration solution and honey was significantly shorter than that in the group receiving only the oral rehydration solution (105.6 \pm 25.7 versus $127.7 \pm 24.5$ hours). The results of our study are consistent with those of studies of Haffejee and Moosa ${ }^{4)}$ and Abdulrhman et al. ${ }^{6)}$ In our study, the comparison of children's weights before and after the intervention showed significant results. Weight gain was prominent in the honey group. This indicates that honey, in addition to accelerating the recovery of diarrhea, results in good weight gain.

Honey has been used in medicine since ancient times. Ancient physicians, such as Aristotle, Hippocrates, and Galen have mentioned various healing properties of honey. ${ }^{9)}$ It is made up of approximately 600 ingredients, including carbohydrates (such as fructose [38.5\%], glucose [31.0\%], maltose, and other sugars), proteins, lipids, minerals (such as calcium and iron), trace elements (such as zinc and selenium), amino acids, antioxidants (such as pinobanksin polyphenols), and other compounds. ${ }^{10-21)}$ There are several different types of honey in terms of moisture content, $\mathrm{pH}$, total acidity, density, dynamic viscosity, refractive index, electrical conductivity, color, amounts of reducing and nonreducing sugars, total sugars, water-insoluble solids, mineral composition, 5-hydroxymethylfurfural content, glycemic index, and diastase value. ${ }^{9)}$ Honey has various healing properties, including antibacterial, antiviral, antioxidant, anti-inflammatory, immune-modulator, and pre-and pro-biotic. ${ }^{9-21)}$ Studies have shown that honey can destroy or control various bacterial pathogens, such as E. coli ${ }^{14)}$ shigella, ${ }^{16)}$ listeria, ${ }^{16)}$ staphylococcus aureus, ${ }^{16)}$ salmonella, ${ }^{14,17)}$ Vibrio cholera, ${ }^{18)}$ and E. coli $\mathrm{O} 157: \mathrm{H} \mathrm{k}^{19)}$ and various viruses, such as herpes simplex, rubella, respiratory syncytial virus, and herpes zoster., ${ }^{9,20)}$ Honey exerts its bactericidal and bacteriostatic effects by various properties and mechanisms, including those involving hydrogen peroxide $\left(\mathrm{H}_{2} \mathrm{O}_{2}\right)$, acidity (low $\mathrm{pH}$ ), antioxidant polyphenols, phenolic components, methylglyoxal, DNA degradation, the interruption of cell division, the blocking of bacterial attachment to tissues, reducing the expression of 2 fibronectin-binding proteins and bee defensin 1, and blocking of biofilm formation. ${ }^{4,6,9,20)}$ The antimicrobial agents in honey are predominantly hydrogen peroxide, of which the concentration is determined by relative levels of glucose oxidase, synthesized by the bee and catalase originating from flower pollen. Most types of honey generate $\mathrm{H}_{2} \mathrm{O}_{2}$ when diluted, because of the activation of the enzyme glucose oxidase that oxidizes glucose to gluconic acid and $\mathrm{H}_{2} \mathrm{O}_{2}$, which thus attributes the antimicrobial activity. ${ }^{20,21)}$ In addition to the antibacterial and antiviral properties of honey, it has been shown that high sugar contents of honey promote sodium and water absorption from the bowel in a manner analogous to the use of oral rice water and sucrose. ${ }^{6}$ This phenomenon can lead to a quick recovery.

According our findings, honey can be prescribed for the treatment of acute diarrhea. Honey is a natural substance, and its consumption is very easy for parents and children. It should also be mentioned that honey removes unpleasant flavors of zinc from zinc syrups and makes them easier to produce. It is also recommended that further studies be conducted with large sample sizes and with different kinds of honey to further support our findings. The limitations of our study were the small sample size and lack of virological investigation.

In conclusion, this study showed that the administration of honey reduced the duration of diarrhea, accelerated the recovery time, and shortened the duration of hospitalization.

\section{CONFLICT OF INTEREST}

No potential conflict of interest relevant to this article was reported.

\section{ACKNOWLEDGMENTS}

We thank and provide our best regards go to the research department of Qazvin University of Medical Sciences and parents of children for their support and cooperation.

\section{ORCID}

Abolfazl Mahyar: https://orcid.org/0000-0002-6418-6372

Parviz Ayazi: https://orcid.org/0000-0002-4808-7999

Mohammad Reza Shaftaroni: https://orcid.org/0000-0002-0487-9767

Sonia Oveisi: https://orcid.org/0000-0003-3106-8043

Reza Dalirani: https://orcid.org/0000-0003-0937-2436

Shiva Esmaeili: https://orcid.org/0000-0001-8981-0680

\section{REFERENCES}

1. Farthing M, Salam M, Lindberg G, Dite P, Khalif I, Salazar-Lindo E, et al. World Gastroenterology Organization global guidelines: acute diarrhea in adults and children: a global perspective. Milwaukee (WI): World Gastroenterology Organization; 2012.

2. Bhutta ZA. Acute gastroenteritis in children. In: Kliegman RM, Stanton BF, St Geme III JW, Schor NF, Behrman RE, editors. Nelson textbook of pediatrics. 20th ed. Philadelphia (PA): Elsevier Saunders; 2016. p. 1854-74.

3. Radlovic N, Lekovic Z, Vuletic B, Radlovic V, Simic D. Acute diarrhea in children. Srp Arh Celok Lek 2015;143:755-62.

4. Haffejee IE, Moosa A. Honey in the treatment of infantile gastroenteritis. Br Med J (Clin Res Ed) 1985;290:1866-7.

5. Eteraf-Oskouei T, Najafi M. Traditional and modern uses of natural honey in human diseases: a review. Iran J Basic Med Sci 2013;16:73142.

6. Abdulrhman MA, Mekawy MA, Awadalla MM, Mohamed AH. Bee honey added to the oral rehydration solution in treatment of gastroenteritis in infants and children. J Med Food 2010;13:605-9.

7. Koh H, Lee MJ, Kim MJ, Shin JI, Chung KS. Simple diagnostic approach to childhood fecal retention using the Leech score and Bristol stool form scale in medical practice. J Gastroenterol Hepatol 2010;25:334-8.

8. Goldman RD. Zinc supplementation for acute gastroenteritis. Can Fam Physician 2013;59:363-4.

9. Israili ZH. Antimicrobial properties of honey. Am J Ther 2014;21:30423. 
10. Gheldof N, Wang XH, Engeseth NJ. Identification and quantification of antioxidant components of honeys from various floral sources. J Agric Food Chem 2002;50:5870-7.

11. Robert SD, Ismail AA. Two varieties of honey that are available in Malaysia gave intermediate glycemic index values when tested among healthy individuals. Biomed Pap Med Fac Univ Palacky Olomouc Czech Repub 2009;153:145-7.

12. Kassim M, Achoui M, Mustafa MR, Mohd MA, Yusoff KM. Ellagic acid, phenolic acids, and flavonoids in Malaysian honey extracts demonstrate in vitro anti-inflammatory activity. Nutr Res 2010;30:650-9.

13. Gannabathula S, Skinner MA, Rosendale D, Greenwood JM, Mutukumira AN, Steinhorn G, et al. Arabinogalactan proteins contribute to the immunostimulatory properties of New Zealand honeys. Immunopharmacol Immunotoxicol 2012;34:598-607.

14. Chauhan A, Pandey V, Chacko KM, Khandal RK. Antibacterial activity of raw and processed honey. Electron J Biolo 2010;5:58-66.

15. Sherlock O, Dolan A, Athman R, Power A, Gethin G, Cowman S, et al. Comparison of the antimicrobial activity of Ulmo honey from Chile and Manuka honey against methicillin-resistant Staphylococcus aureus, Escherichia coli and Pseudomonas aeruginosa. BMC Complement Altern Med 2010;10:47.

16. Taormina PJ, Niemira BA, Beuchat LR. Inhibitory activity of honey against foodborne pathogens as influenced by the presence of hydrogen peroxide and level of antioxidant power. Int J Food Microbiol 2001;69:217-25.

17. Mulu A, Tessema B, Derbie F. In vitro assessment of the antimicrobial potential of honey on common human pathogens. Ethiop J Health Dev 2004;18:107-12.

18. Molan PC. The antibacterial activity of honey: 1 . the nature of the antibacterial activity. Bee World 1992;73:5-28.

19. Lee DS, Sinno S, Khachemoune A. Honey and wound healing: an overview. Am J Clin Dermatol 2011;12:181-90.

20. Mandal MD, Mandal S. Honey: its medicinal property and antibacterial activity. Asian Pac J Trop Biomed 2011;1:154-60.

21. Khan FR, Ul Abadin Z, Rauf N. Honey: nutritional and medicinal value. Int J Clin Pract 2007;61:1705-7. 